\title{
Knowledge, beliefs, and perceptions of tuberculosis among community members in Ntcheu district, Malawi
}

This article was published in the following Dove Press journal: Journal of Multidisciplinary Healthcare

\author{
Peter Nyasulu, ${ }^{1,2}$ Simon \\ Sikwese, ${ }^{2,3}$ Tobias Chirwa, ${ }^{2}$ \\ Chandra Makanjee, ${ }^{4}$ Madalitso \\ Mmanga, ${ }^{5}$ Joseph Omoniyi \\ Babalola, ${ }^{6}$ James Mpunga, ${ }^{7}$ \\ Hastings T Banda, ${ }^{8}$ Adamson S \\ Muula, ${ }^{9,10}$ Alister C Munthali' \\ 'Division of Epidemiology and \\ Biostatistics, Faculty of Medicine and \\ Health Sciences, Stellenbosch University, \\ Cape Town, ${ }^{2}$ School of Public Health, \\ Faculty of Health Sciences, University of \\ the Witwatersrand, Johannesburg, South \\ Africa; ${ }^{3}$ Pakachere Institute of Health \\ and Development Communication, \\ Blantyre, Malawi; ${ }^{4}$ Department of \\ Medical Radiation Sciences, University \\ of Canberra, Canberra,WA, Australia; \\ ${ }^{5}$ District TB Office, Department of \\ Environmental Health, District Health \\ Office, Ntcheu, Malawi; ${ }^{6}$ Division of \\ Community Paediatrics, Faculty of \\ Health Sciences, University of the \\ Witwatersrand, Johannesburg, South \\ Africa; ${ }^{7}$ National Tuberculosis Control \\ Program, Community Health Sciences \\ Unit, Ministry of Health, Lilongwe, \\ ${ }^{8}$ Research for Equity and Community \\ Health (REACH) Trust, Lilongwe, \\ 'Department of Community Health, \\ College of Medicine, University of \\ Malawi, Blantyre, ${ }^{10} \mathrm{African}$ Centre \\ of Excellence in Public Health and \\ Herbal Medicine, College of Medicine, \\ University of Malawi, Blantyre, "Centre \\ for Social Research, University of Malawi, \\ Zomba, Malaw
}

Correspondence: Peter Nyasulu

Division of Epidemiology and Biostatistics,

Faculty of Medicine and Health Sciences,

Stellenbosch University, Francie van Zijl

Drive, Tygerberg, Cape Town 7505, South

Africa

Tel +27 2l 9389886

Email pnyasulu@sun.ac.za
Introduction: The global burden of tuberculosis (TB) remains significantly high, with overreliance on biomedical interventions and inadequate exploration of the socioeconomic and cultural context of the infected population. A desired reduction in disease burden can be enhanced through a broader theoretical understanding of people's health beliefs and concerns about TB. In this qualitative study, we explore the knowledge, beliefs, and perceptions of community members and people diagnosed with TB toward TB in Ntcheu district, Malawi.

Methods: Using a qualitative phenomenological study design, data were obtained from eight focus-group discussions and 16 individual in-depth interviews. The community's experiences and perceptions of TB were captured without using any preconceived framework. Adult participants who had had or never had a diagnosis of TB were purposively selected by sex and age and enrolled for the study. Discussions and individual interviews lasting about 60 minutes each were audiotaped, transcribed, and translated into English and analyzed using MaxQDA 10 software for qualitative analysis.

Results: Most participants believed that TB was curable and would go for diagnosis if they had symptoms suggestive of the disease. However, based on their beliefs, individuals expressed some apprehension about the spread of TB and the social implications of being diagnosed with the disease. This perception affected participants' responses about seeking diagnosis and treatment. Conclusion: A supportive and collective approach consisting of a combination of mass media, interactive communication campaigns, emphasizing TB symptoms, transmission, and stigma could be useful in addressing barriers to early diagnosis and care-seeking behavior.

Keywords: tuberculosis, knowledge, perception of TB, beliefs, Ntcheu, Malawi

\section{Introduction}

Tuberculosis (TB) which is caused by Mycobacterium tuberculosis, a tubercle bacillus, is a major public health problem globally. ${ }^{1}$ The global burden of TB remains significantly high, and reasons for this include delays in diagnosis, case detection, and treatment seeking and poor treatment adherence. ${ }^{2-10}$ Such factors have negatively affected morbidity and mortality and potentiated the spread of TB to other people. There has been overreliance on biomedical interventions without adequate consideration of the social, cultural, and economic environment of infected people and the community at large. ${ }^{9-16}$ To achieve the desired decline in TB incidence and prevalence, people's knowledge of, attitudes toward, and perceptions of TB need to be understood. These could contribute to the development and implementation of effective community-based health-promotion programs in many countries. ${ }^{11}$ A broader theoretical understanding of people's health beliefs and concerns about TB can inform and clarify existing 
perceptions and misconceptions and enhance a better understanding of the gravity of TB disease. ${ }^{17,18}$ These beliefs might thus be better shaped by such factors as social support, access to timely diagnosis, and appropriate treatment facilities. ${ }^{12,17,18}$

The Millennium Development Goal targets for 2015 of reducing TB prevalence and deaths by half globally has made some impact on the burden of targeted diseases, including TB. ${ }^{13}$ Yet, persisting challenges reinforced by social inequalities, abject poverty, and uneven developmental progress need to be better understood. The World Health Organization (WHO) further set targets to reduce the burden of TB by half by $2050 .{ }^{14}$ The directly observed treatment, short course (DOTS) Stop TB campaign and early case detection are central to global TB control. ${ }^{9,15,19}$ Despite the global decline in TB in several countries with the DOTS initiative, the much-anticipated success fell below expectations. As such, TB remains a matter of concern due to continued direct and indirect modes of transmission, including the status of undiagnosed cases within the community. Delays in diagnosis and case detection, which serve as important barriers to effective TB control, are major challenges that might be due to inadequate knowledge about the cause, mode of transmission, and symptoms associated with TB. Perceptions and beliefs that members of communities have about TB are important factors that help shed more light on why diagnosis may be delayed..$^{20-23}$

High HIV-infection rates in sub-Saharan African countries, including Malawi, have contributed to the resurgence of TB in the past two decades. While Malawi's National TB Control Programme has been recognized internationally for its effective approach to TB control, its impact has been affected by the HIV epidemic, which has resulted in an increased number of TB cases. ${ }^{24}$ Malawi registered 28,200 cases of TB in 2003, largely resulting from the HIV epidemic in the country. ${ }^{25}$ A WHO report on Malawi as of 2015 indicated a total TB incidence of 193 per 100,000 population, with HIV coinfection accounting for about $54 \%$ of cases. ${ }^{26}$ One of the major challenges of the TB-HIV link in Malawi is stigma. ${ }^{27-29}$ Although a biomedical model has been used to show the effectiveness of the DOTS strategy in TB control, gaps exist in the overall impact of the DOTS strategy in its ability to effectively tackle factors affecting human behavior. ${ }^{1,30}$ Few TB-control programs incorporate patients' perspectives about the disease, which is often affected by their level of socioeconomic status and cultural factors. This also includes people's beliefs and the effect of these beliefs on patients' care-seeking behavior. ${ }^{1,30}$

Effective health-care seeking is influenced by factors at the level of the health system, community, family, and individual preferences. Such health-care-seeking behavior is also affected by expectations, experiences, knowledge, and perceptions, including how to deal with symptoms and illnesses. ${ }^{5,20}$ Therefore, it is critical to use a holistic approach that includes biomedical, socioeconomic, and cultural aspects, in order to foster improved solutions to detect new cases and minimize delayed TB diagnosis..$^{2,5-7,19,31}$ There are limited data on the social and cultural aspects of TB, as most studies have mostly focused on clinical and operational research. ${ }^{32}$ This study, conducted in Ntcheu district in the central region of Malawi, was focused on understanding community perceptions, beliefs, and knowledge about TB. The rationale was that looking at these issues would provide a pathway to understanding people's health-seeking behavior and factors affecting early diagnosis. The outcomes from this study would contribute to the designing and implementation of TB community-outreach programs and inform the development of a health-education model to correct misconceptions, erroneous beliefs, attitudes, and perceptions for the rural community in districts of Malawi. ${ }^{1,12,18}$ Such results would in turn also improve early diagnosis and treatment-seeking behavior. The aim of this study was to explore adult men's and women's perceptions of TB, how they constructed their understanding, attitude and knowledge, and to establish how they experienced the disease itself within the context of biomedical health-seeking behavior and within the community, society, and family in a rural community in Ntcheu district.

\section{Methods \\ Study design}

This was a qualitative phenomenological study design. A phenomenological approach, which identified and describes the essence of lived experiences of the participants, ${ }^{33}$ was used to explore knowledge, beliefs, and perceptions about TB among adult men and women without TB experience and persons with previous TB history. The study aimed at accurately capturing the community's experiences and perceptions of TB without using any preconceived framework. ${ }^{34}$

\section{Study setting}

The study was carried out in three villages - Kambuku, Majiri, and Mwadzangati - in the Traditional Authority (TA) of Makwangwala in Ntcheu district, which is in the central region of Malawi. The choice of study setting was influenced by the feasibility of conducting the study, including ease of mobility and transport-related costs to the investigators, as the fieldwork was done during a fuel crisis. Ntcheu is $3,424 \mathrm{~km}^{2}$ in size and has a population of $474,464 .{ }^{35}$ Most of Ntcheu is 
classified as rural, and it has 192,183 persons aged $18+$ years. $^{35}$ The district has ten TAs, and the dominant tribe is Ngoni. It has one district hospital, two community hospitals, 21 health centers, and four dispensaries. TA Makwangwala is $681 \mathrm{~km}^{2}$ in size, has four group village chiefs, and 66 villages, with a population of 48,388. It has six health centers. Ntcheu was selected because it is one of the districts with high TB burden in Malawi, with an estimated prevalence of 57 per $100,000 .^{36}$

\section{Study population}

The study population comprised men and women aged 18-49 years living in the villages which fall under the jurisdiction of TA Makwangwala in Ntcheu district. This age-group was selected because TB is said to affect the most productive ages in poor countries, such as Malawi. ${ }^{37}$ This is mostly because of HIV coinfection. Participants in this study were those who had never been diagnosed with TB and those with a history of TB.

\section{Sampling}

Participants for the study were purposively selected for sex, age, and whether they had been diagnosed with TB or not to ensure substantial contributions to and obtainment of rich data. Male and female participants were interviewed separately to ensure that their participation was not affected by male domination and for appropriate comparison of male and female perspectives (Table 1).

\section{Data-collection process}

Potential participants - persons who had never had TB (NHTB) and "ever had TB" (EHTB) referring to persons who had been diagnosed with TB - were recruited with the assistance of the chief's councilors or any person designated by the chief. Health-surveillance assistants, whose responsibility, among others, was to follow up people diagnosed with TB and ensure treatment adherence, were engaged in enrolling participants. ${ }^{38}$ These assistants used medical records to identify suitable TB-diagnosed participants. Participants were informed, and prior verbal consent was obtained. A total of 16 in-depth interviews (IDIs) involving six males and six females in the NHTB group and two males and two females in the EHTB group were conducted at a place convenient to the participants, ie, their homes, until data saturation. Participants preferred to be interviewed in the afternoons, because they worked in the gardens in the mornings. In addition, there were eight focus-group discussions (FGDs) with each FGD consisting of eight to ten participants. Two FGDs were held among EHTB persons and six FGDs were held among NHTB participants until data saturation (Table 1). FGDs took place in a classroom or the chief's court, whichever was convenient.

\section{Data-collection instruments}

Interview guides for IDIs and FGDs were developed and used for data collection after being piloted. Guides were designed on the premise that data collected would provide in-depth information that would effectively address the issues that were being investigated in this study. Key probes for discussion included participants' knowledge about the disease itself and causes and modes of transmission. NHTB participants' perceptions and opinions regarding TB and TB-diagnosed people were also explored. During interviews, participants shared why they held a particular view and described what they thought about being diagnosed with TB. They discussed the signs and symptoms of TB and what it is like to be labeled locally as having TB. For EHTB participants, we also explored views on how they felt about how the community, friends, and family perceived and treated them. These interview guides were translated into Chichewa and back-translated into English by different people and checked for consistency. All interviews and FGDs were conducted in Chichewa and digitally recorded. Notebooks and pens were also provided for recording observations made during the IDIs and FGDs. Both FGDs and IDIs lasted for approximately 60 minutes. There were two research teams, and each team was involved in FGDs and IDIs for 10 days.

\section{Training of data collectors}

Prior to data collection, four research assistants received training for 2 days to ensure that data collection was

Table I Sampling breakdown

\begin{tabular}{|c|c|c|c|c|c|c|c|c|c|}
\hline \multirow{3}{*}{$\begin{array}{l}\text { Data-gathering } \\
\text { method }\end{array}$} & \multicolumn{6}{|c|}{ Never-had-TB group in the villages } & \multirow{2}{*}{\multicolumn{2}{|c|}{$\begin{array}{l}\text { Ever had TB } \\
\text { Pooled }\end{array}$}} & \multirow[t]{3}{*}{ Total } \\
\hline & \multicolumn{2}{|c|}{ Kambuku } & \multicolumn{2}{|c|}{ Majiri } & \multicolumn{2}{|c|}{ Mwadzangati } & & & \\
\hline & Male & Female & Male & Female & Male & Female & Male & Female & \\
\hline IDIs & 2 & 2 & 2 & 2 & 2 & 2 & 2 & 2 & 16 \\
\hline FGDs & I & I & I & I & 1 & I & I & I & 8 \\
\hline
\end{tabular}

Note: Each FGD consisted of eight to ten participants.

Abbreviations: TB, tuberculosis; IDIs, in-depth interviews; FGDs, focus-group discussions. 
consistent. The training covered the objectives of the study and the methods of data collection. The training also covered thorough understanding of the guides for both IDIs and FGDs, and assistants were oriented on how to use digital recorders, transcribe responses, and translate the data. The guides for FGDs and IDIs were piloted by the Blantyre district, and interview guides were adjusted and adapted accordingly prior to actual data collection.

\section{Data management and analysis}

Audio-recorded IDIs and FGDs were captured on a computer and backed up immediately after an interview. Each interview was identified by an audio-recorded voice indicating the type of interview, age range, sex, and whether it was for the EHTB or NHTB. Audio-recorded data were transcribed verbatim in Chichewa by assistants soon after interviews. Translation into English was done immediately thereafter in Microsoft Word. Transcripts were checked specifically for spelling and grammatical errors prior to importing them into MaxQDA 10. Where necessary, the accuracy of the captured data and analysis thereof was checked and rechecked by the primary investigator to verify that meaning had not been altered. Data were read through several times and text segments coded to develop theory and identify themes. Inductive content analysis was employed using MaxQDA 10 for qualitative data analysis. This involved identification of recurring patterns and themes relating to people's perceptions regarding TB. The themes identified were used to develop a model that explained the perceptions and beliefs that individuals had in the community and how these may affect care-seeking and treatment-adherence behavior. Themes emerging from interviews and FGDs were compared among EHTB and NHTB individuals. This is further elaborated in the result section.

\section{Study limitations}

At the time of the study, its main limitation pertained to access to research participants, due to a fuel crisis in the country, which might have led to selection bias. In addition, limited responses could have been obtained due to the sensitive nature of TB and its association with HIV infection, which carries high levels of stigma and discrimination, and also its negative implications on marital relationships. Lastly, the study was conducted in three villages of one rural community, making it difficult to generalize the findings to other settings.

\section{Ethical consideration}

The study was approved by the University of the Witwatersrand Human Research Ethics Committee (approval number M110956) and the National Health Sciences Research Committee, Lilongwe, Malawi. In addition, each village chief gave approval to conduct the study in their area. Participation in the study was voluntary, with participants free to withdraw at any time, as stated on the informed-consent form.

\section{Results}

Based on interpretation of the results, themes and subthemes emerged: TB is a "very difficult disease"; health-systemrelated issues and diagnosing $\mathrm{TB}$; resource constraints and real-world challenges; and the supportive role of significant others.

\section{TB "a very difficult disease"}

This is one of the prominent themes that emerged from the study. There were variations in people's perceptions about TB. Participants in both groups perceived TB as being a dangerous disease, prior to diagnosis in those who already experience the signs and symptoms:

$\mathrm{TB}$ is a dangerous disease especially when one has not yet been diagnosed but he/she is showing signs and symptoms of the disease. [male, IDI, EHTB]

NHTB participants who acquired information from other sources about the complexity of this illness particularly mentioned continuous coughing:

What I have heard is that TB is a very difficult disease and one coughs uncontrollably. [male, FGD, NHTB]

The progressive illness status and seriousness of illness was also related to delayed diagnosis and delayed commencement of treatment:

This disease becomes very dangerous if a person has delayed in taking its treatment or if you have started taking its treatment while it has reached at an advanced stage. [male, IDI, EHTB]

Physical pain emerged as the most common experience of TB. Coughing, in particular, was identified as a source of pain by all participants. Shortness of breath had a negative impact on the functional ability of the individual:

Eeeh, the person also feels pain in side of the chest more, especially when breathing and sleeping on one side. [male, FGD]

[...] and a person who is suffering from TB cannot work properly and he/she have difficulties when breathing. [female, FGD, NHTB] 


\section{TB-risk perceptions}

Participants were asked about their likelihood of acquiring TB. Most responded by saying that anyone is at risk of contracting TB, because it is an airborne disease and can be acquired through inhaling contaminated air:

Because it transmits through the air, so we all breathe the air, so it is likely to get it if you are staying close to the person suffering from TB. [female, FGD]

In my view, I cannot say that there is specific group of people which is entitled to suffer from TB. Every person can suffer from this disease because it gets spread through the air. [male, IDI, EHTB]

Some NHTB participants said that lack of knowledge about TB symptoms is one of the reasons that people fail to report early to the hospital for TB diagnosis:

They don't have the knowledge of the disease, they just hear it from their friends and then become afraid of the syringes, injections, and some people don't like pills. [female, FGD, NHTB]

\section{The spread of TB}

Although participants demonstrated high knowledge of how TB is transmitted using the germ theory, there were misconceptions about how TB is spread. However, they mentioned breathing contaminated air, smoking, sex, and alcohol as some of the possible ways in which TB is transmitted:

Smoking, when the person is smoking tobacco, the smoke damages his lungs and once the lungs are damaged he develops TB. [male, FGD, NHTB]

Others believed one could get TB by sleeping in the same room with a person who has TB who releases the germs in the air, and that one can get infected by breathing that air:

But others can get it by sleeping in close contact with infected people, especially when they have not started taking drugs, sleeping in one house with infected people, but also when caring for a TB patient, a person exposed can get it. [female, FGD, NHTB]

An interesting fact was that few NHTB participants were of the belief that sexual intercourse had a role to play in the transmission of TB-associated HIV. These participants further elaborated on distinguishing between "normal" TB, which one gets through breathing contaminated air, versus the one associated with HIV based on their prior knowledge that HIV is transmitted through unprotected sexual intercourse:
TB came a long time ago, but now it comes in different ways: one can get TB through sexual promiscuity (chiwerewere) and through the natural way (yachilengedwe). [female, FGD, NHTB]

There are few people who contract TB through the natural way, but through sex there are a lot of people who contract the disease, so when one has TB through sex, then automatically she must know that she has two kinds of diseases, ie, TB and HIV [female, FGD, NHTB]

Study participants were asked about the anatomical sites of TB. NHTB participants seldom mentioned TB sites of infection, but did by means of describing the symptoms, such as coughing associated with pulmonary TB. EHTB participants were able to distinguish between pulmonary TB and other sites, such as "TB of the bones", because they had had it at that particular site. Others were familiar regarding the various sites through interaction with either friends or relatives who had had the disease and during a medical consultation process. "TB of the bones" was reported to be more dangerous and complex than TB affecting the lungs. A participant shared a story about a boy in his village who had TB of the bone and his journey through the health system:

For example, there was a boy in this village who had TB that affects the bones, but he did not know that what he was suffering from was TB of the bones. He went to Bilila Health Centre, but they did not discover the disease, up to Ntcheu District Hospital, but they did not discover the disease as well, then he went to Queen Elizabeth Central Hospital for $\mathrm{X}$-rays for so many times, but they too did not discover the disease, then the doctor said that he was suspecting that the boy was suffering from TB of the bones and they put him on TB drugs and eventually he was well again, and as I am talking to you now, the boy is ok, so I think there are different types of TB: one is not difficult to find and the other one is difficult to discover it. [female, FGD, NHTB]

\section{TB coupled with HIV}

Several EHTB women held the view that if a person is diagnosed with TB, he/she is likely to have HIV, and in only rare circumstances is this not the case:

TB came long time ago before HIV, so nowadays it is very rare to be found with TB only. As a result, when one is suffering from TB, automatically he has HIV. [female, FGD, NHTB]

This assumption was triggered mainly by the physical appearance of the person diagnosed with TB: 
They spoke negatively about us. Most of them were saying we have AIDS, and especially because we became thin and weak, they took that for AIDS. [female, FGD, EHTB]

\section{Identifying TB "suspects”}

Participants were asked how they could tell if they suspected that an individual in the community might be suffering from TB before being diagnosed with the disease. Most participants, both NHTB and EHTB, mentioned coughing as a sign of people infected with TB:

I was coughing, but I was not producing sputum, and after I coughed up to 3 weeks I went to Ntcheu, where I was diagnosed with shortage of blood in my body. [male, FGD, EHTB]

Others cough a lot, others it comes through the bones, but it is difficult to discover it unless the patient is coughing, when someone is coughing for several weeks. [female, FGD, NHTB]

When you see that you have a continuous cough, you have to go to the hospital and give out sputum for TB screening. [female, IDI, NHTB]

In the local language, "chifuwa cha chikulu", which literally means "big cough", was a common symptom that both male and female participants mentioned. The significance of the local expression "big cough" is that it is used to describe the long duration of cough that may last for weeks or even months and accompanied difficulty with breathing seen among those with TB, as different from other transient episodes of cough with no associated distress.

EHTB participants also mentioned night sweats and production of sputum as some of the symptoms of TB, which was not mentioned by participants who had never had a past history of TB:

I was producing more sweat at night, and I was failing to sleep using one side for a long time. [male, IDI, EHTB]

I was coughing, but I was not producing sputum, and after I coughed up to 3 weeks I went to Ntcheu, where I was diagnosed with shortage of blood in my body. [male, FGD, EHTB]

\section{Health-system-related issues and diagnosing TB}

Most participants described the progress of their illness as they journeyed through the various levels of the health system to seek a definite diagnosis. Often, people were shunted to and fro within different health facilities during this period, as illustrated by the participant below. This participant also perceived that X-ray is a measure of treatment intervention:

I suffered a lot. I went to different hospitals like Bilila Health Centre, and then I was told to go to Ntcheu District Hospital for further screening. I was feeling back pains, pain in the joints, sweating a lot during the night, fever [in] the whole body. Those were the signs, but when I went to Ntcheu District Hospital I was only given the tablets instead of X-ray, because that was what I was told at Bilila Health Centre. [male, IDI, EHTB]

In some instances, medical providers had given up on patients and resorted to prescribing them with tablets for pain relief. These types of encounters left the individual with a sense of helplessness:

I asked the doctors what next, and they told me that there was nothing they could do, except to prescribe me with the medicine to reduce the pain which I was feeling that time, and I was told to buy the medicine at a pharmacy. [male, IDI, EHTB]

With the help of his parents, the patient went to hospital in Blantyre city, where he had X-rays five times, but TB was not diagnosed. He was later tested for HIV, but was found negative, and the doctors decided to put him on TB treatment and observe for 21 days to see if there was any improvement. A few days after the commencement of the treatment, the condition improved, and the doctors recommended that he finish the TB treatment. At the time of the interview, the participant was still on treatment and was looking healthy:

[...] I am talking from experience, because I was strongly troubled by this disease. I was admitted three times while being given several drips, bottles for sputum, and until the third time when I was taken for X-raying then they found it. I stayed there but was heavily affected by the TB. I was so weak, because I could not eat, as each time I ate I was vomiting. I was frequently found with fever and had no peace in my heart, but when I started taking the drugs, I have seen great improvements because I am now eating just as I used to. I failed to cook, but now I can cook. I was not able to carry a bucket of water on my head, but now am able to do so, and I believe the TB drugs are very strong and have cured me. [female, FGD, EHTB]

\section{The success of medical intervention}

Participants were asked to express their views regarding how they would feel and react if they were diagnosed with TB and 
what they think about people who have been diagnosed with TB. This was done in order to establish their perceptions of being infected with TB. Participants seemed to accept the reality of TB disease when diagnosed and were adherent to the treatment strategy prescribed as described by these two participants:

I cannot be worried, because treatment or rather drugs for TB is always there, and if taken according to doctor's advice, one is able to get cured. [male FGD]

I cannot be disappointed, because the disease is already in my body, but rather I will just accept it and follow the doctor's advice and instructions. [female, FGD, NHTB]

\section{TB is curable}

Participants across all FGDs believed TB was curable. Participants, especially EHTB, believed that if diagnosed and treated early at the hospital, they would be cured. They also reiterated the importance of following the doctor's advice:

If one follows the doctor's advice, it is easy to get cured from TB. It is a good drug, one just has to choose time to take the drugs every day. You can choose to drink it in the evening or morning or even afternoon. You don't have to carry with you the drugs everywhere you go. [male, FGD, EHTB]

Participants were also cognizant of the role of TB drugs in curing TB, in addition to seeking help at a hospital:

When you have been found with TB, you can start taking the drugs and you can be healed. [female, IDI, NHTB]

Some EHTB participants testified on how adhering to treatment by taking the "strong" drugs led to their recovery. The progressive healing was measured by the ability to resume their daily tasks that they did prior to being diagnosed with $\mathrm{TB}$ :

But when I started taking the drugs, I have seen great improvements, because am now eating just as I used to. I failed to cook, but now I can cook. I used to fail lifting up buckets, but now am able to, and I believe the TB drugs are very strong and have cured me. [female, FGD, EHTB]

\section{The role of complementary medicine in managing TB}

The use of traditional healers was another reason people delayed getting a diagnosis. Participants mentioned various reasons why some people go to traditional healers. Some mentioned the belief in religious teaching that prohibits use of modern medication, the belief that they have been "bewitched", and lack of knowledge of what they are suffering from. While participants said this, other participants, both male and female, were quick to mention that it is only at the hospital that one can be diagnosed and be cured of TB:

“... some people who rush to the traditional doctors to seek medicine for TB thinking that someone has bewitched them instead of going to the hospital for treatment. [female, IDI, NHTB]

Of course, some, they do access from traditional healers, but three-quarters, they access TB services from the hospitals. [male, IDI NHB]

\section{Resource constraints versus real-life challenges}

The costs incurred due to frequent hospital visits are a contributing factor in delayed access to proper treatment. Participants felt that there was a lot of time wasted as individuals traveled to and from hospital and spent less time in the garden working:

Others, they think that they will be busy going to and from the hospital for TB treatment instead of being at home working. [male, IDI, NHTB]

Some NHTB participants and those on TB treatment said that lack of money for a bus fare makes them unable to travel to the hospital to collect the drugs, and as such makes them not adhere to treatment sometimes:

An example is myself. I was supposed to go today, but I don't have transport money to go to the hospital to take the drugs. You can check on my papers: I have them with me. I was diagnosed on 20th November. I was given the drugs for TB for 2 months, and after screening for TB, it was found out that the TB was gone. The other paper is with the volunteer. You can check; I don't hide them. [male, FGD, EHTB]

\section{Issues pertaining to lifestyle adaptations}

EHTB participants reported that when one is diagnosed with $\mathrm{TB}$, he or she is told to change some behavior, such as refraining from alcohol, smoking, and reducing the frequency of having sex. People are thus afraid of going for diagnosis for fear of being diagnosed with TB, which will result in them being told to stop some of these behaviors:

There are a lot of reasons people don't go to the hospital for treatment. There are other people who heard that when one is on TB treatment, he/she is not supposed to do this and that so they don't want to be told to stop some of the things 
which to them make them happy. They are shy to face the doctors and be told to stop some of the things which they do, and they know that they cannot stop doing them, even if they are told to stop by the doctors. [male, IDI, EHTB]

I was told not to drink alcohol, not to smoke, not to have sex with my wife up to 6 months (up to the end of the treatment). [male, FGD, EHTB]

\section{Supportive role of significant others}

Participants indicated that TB patients required physical and emotional support without discrimination. Sex roles influenced the reactions and responses of women and men, with women playing more caregiving roles as wives, daughters, and relatives than the men. Females not only offered more supportive views than males, but they also reported that people who have TB should be given emotional support, which should include loving and encouraging them to take their drugs. These views are evident from these contributions:

I was taken care of by my wife. There are times when people discriminate [against] someone who has TB, but my wife was able to wash the bottles which I was using; she was able to escort me to the toilet, because I was failing to walk. I was weak, even my relatives were there for me, I was not discriminated [against]. [male, FGD, EHTB]

Like for me, when I fell sick, my granddaughter looked well after me until I got all the medication. My relatives and friends supported me, and nobody discriminated against me. We were sleeping in one house. [female, FGD, EHTB]

We must not discriminate [against] them; rather we should or must take care of them and take them as our fellow human beings. [female, IDI, NHTB]

When someone is sick, he/she sees everything. He must worry about his sickness, but not the way we are treating them. We must show some love and take care of them for $\mathrm{him} /$ her to feel good. [female, IDI, NHTB]

Women reported offering support to TB patients by encouraging them to eat. They said that some people with TB do not have any appetite, and as such they need to be encouraged. The support also included preparing food for them:

There are others who do not have appetite to eat, but the best way is to encourage them to eat so that the drugs should work properly in their body. [female, FGD, NHTB]

\section{Discussion}

This study has provided insights into community members' perceptions of TB and how this affects health-seeking behavior and quality of life. It was demonstrated in this study that there are differences in levels of knowledge and perceptions about TB between those EHTB and NHTB groups. EHTB participants highlighted some health-system issues that have an impact on the diagnosis and treatment of TB. For example, participants shared narratives of misdiagnosis that resulted in delayed treatment initiation.

They also mentioned costs incurred related to repeated travel to and from hospital. Experiences of stigma and discrimination within the community primarily due to the perceived TB coupled with HIV were also shared. These narratives highlight the interplay of factors at individual, household, and community levels and how they affect TBrelated health-seeking behavior, diagnosis, and treatment. ${ }^{18,39}$

These findings are better understood by applying the social ecological model (Figure 1), a multilevel framework for understanding behavior and tools for designing possible interventions, taking into consideration the complex multilevel environments of individuals. The social ecological model shows that knowledge, beliefs, and perceptions of individuals are influenced by interaction with family, friends, work environment, health systems, and policies. The interplay of the different factors at various levels of the social ecological model and how they affect people's ability to go for early diagnosis is displayed in Figures 1 and 2. Figure 2 shows a model that explains early health-seeking behavior and how individuals' intentions to seek services and decision-making for health care is affected by their knowledge levels, perceived risk, and perceived severity of TB.

\section{Individual-level factors}

Individual-level factors dealt with knowledge, beliefs, attitudes, and skills that a person needed to reduce the risk of TB and improve health and well-being. In this study, it was apparent that experiencing the illness itself or being closely affiliated with an person with $\mathrm{TB}$ enhances the ability to recognize the signs and symptoms. This also helps the understanding and contextualizing of a TB patient's lifeworld experiences. Also, knowledge leads to understanding of taking informed action, but does not directly lead to action. Comprehensive knowledge of other signs and symptoms of TB was also due to the interaction they may have had with health-service providers, who may have provided health-related information regarding TB. A study conducted in Zomba in Malawi found that lack of knowledge about TB was one of the main reasons causing delay, among people suspected of having TB, to seek early diagnosis. ${ }^{40}$ The promotion of healthy behavior principally involves knowledge dissemination, which impacts and 


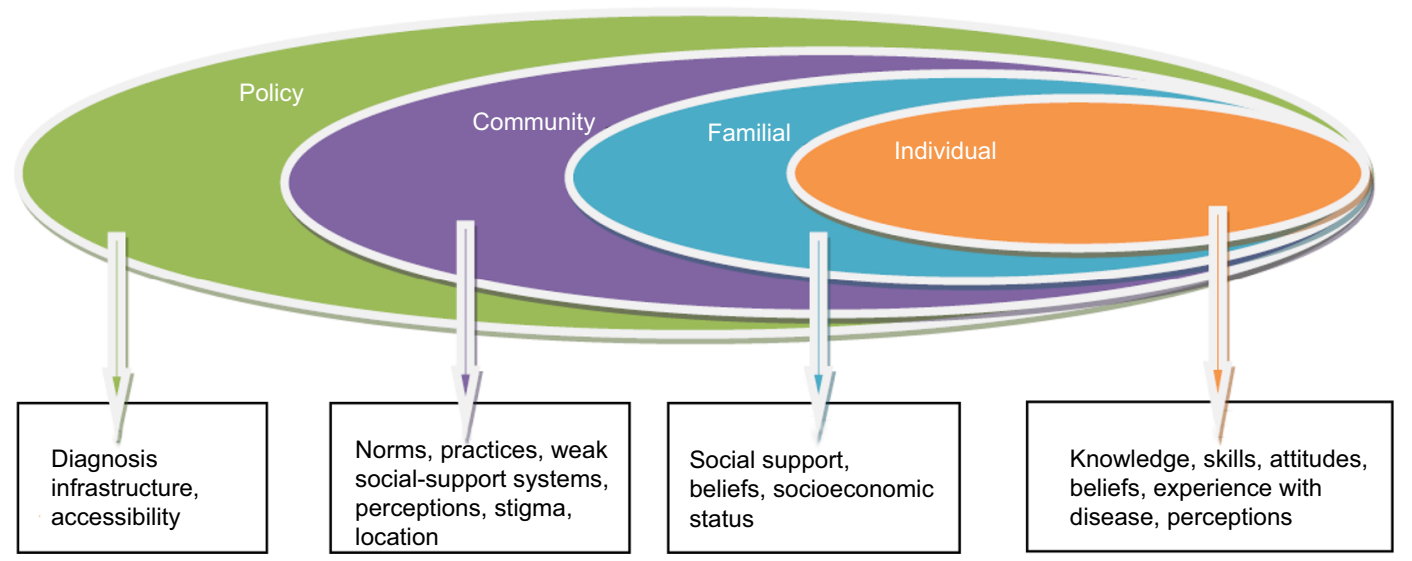

Figure I Social ecological model.
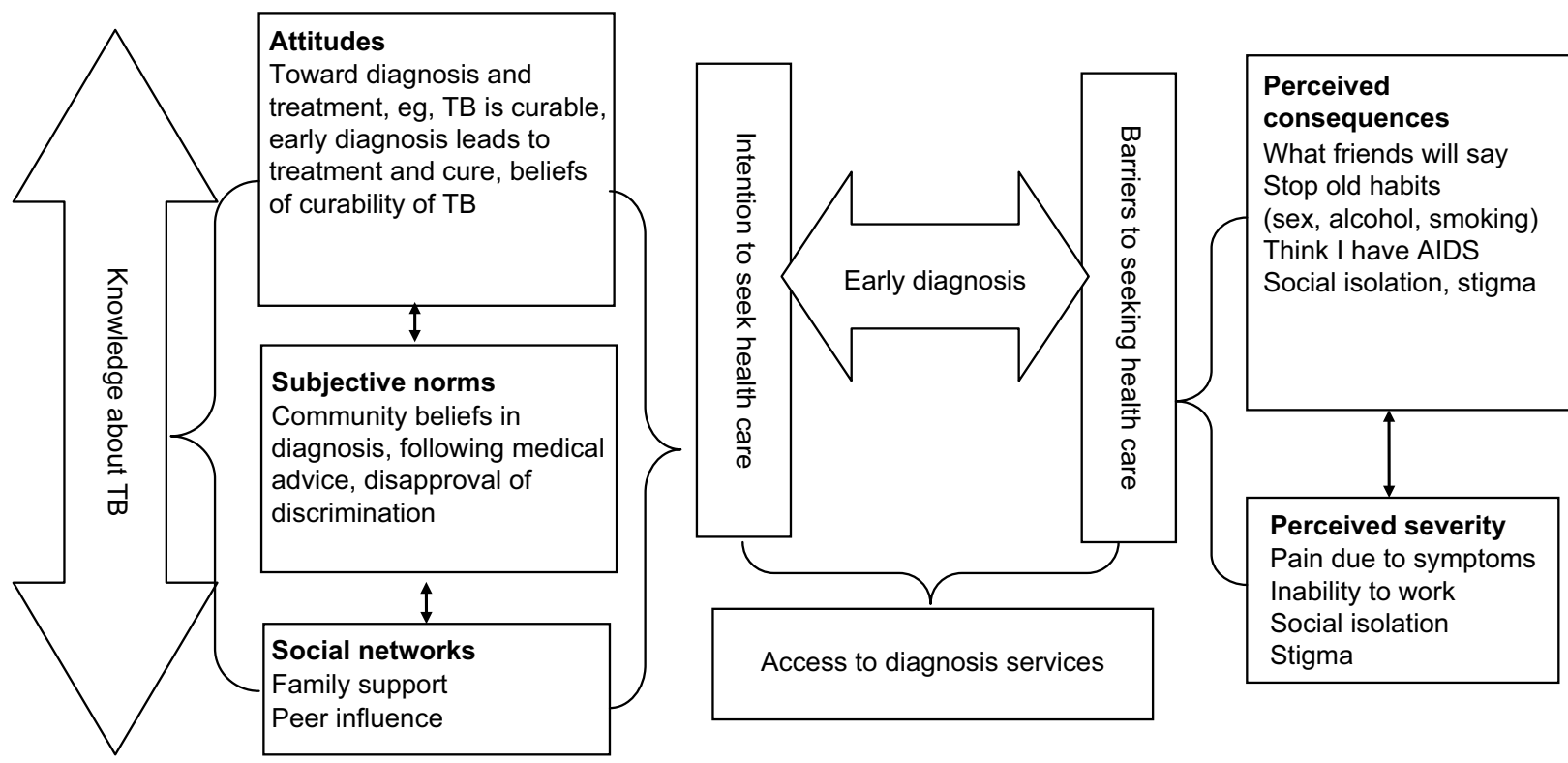

Figure 2 Model of early diagnosis-seeking behavior.

Note: Interplay of how early diagnosis-seeking behavior of individuals, intent to seek services, and decision-making are affected by individuals' knowledge levels, perceived consequences, and perceived severity of TB.

Abbreviation: TB, tuberculosis.

influences attitudes and beliefs. ${ }^{41}$ According to van Zundert et al, social cognitive theory states that "cognitive factors such as outcome expectations, self-efficacy and intentions are also important determinants of behavior". ${ }^{42}$ In the context of TB, the knowledge that TB is curable can be a factor that influences a person toward going for early diagnosis. Other factors, such as social support from peers, can increase an individual's intentions to go for early diagnosis. ${ }^{43,44} \mathrm{In}$ Figure 2, knowledge cuts across the model, because the depth of knowledge that a person has can have an influence on their ability to act differently.

\section{Knowledge of TB transmission}

Important knowledge of the mode of transmission of TB was shown by most participants, who mentioned that TB is spread through the air. However, similarly to findings from another study, misconceptions were common among male participants on the causes of TB. They were of the opinion that smoking, alcohol, and sex were some of the ways people acquire TB. ${ }^{21}$ Unlike in other studies, where knowledge about germ theory was found to be very low and people attributed TB to witchcraft or God, some participants in this study demonstrated knowledge of germ theory. ${ }^{45,46}$ They reported 
that a person with TB releases germs in the air and another can get infected by breathing contaminated air. The fact that this misinformation persists shows that health-promotion messages have not tackled these misconceptions. The factors mentioned are related to TB spread: sex is not a mode of transmission but may facilitate transmission due to proximity. Tobacco smoking is an understood risk factor for TB/chronic obstructive pulmonary disease, and alcohol consumption may lead to undernutrition, which in turn predisposes one to developing TB. TB-control programs need to address areas of misconceptions and provide health education, which must include appropriate advice and clarify the route of transmission versus spread specific to intimacy and sex, when initially diagnosed.

\section{Knowledge of TB infectivity}

Transmission of TB is controlled through early detection of cases and prompt commencement of anti-TB chemotherapy. ${ }^{47}$ In order to prevent new infections, it is essential that individuals are able to identify TB infections through knowledge of signs and symptoms. The ability to do that could significantly contribute to early diagnosis. This will subsequently lead to early treatment and reduced risk of infection within communities. ${ }^{48}$ There was general lack of knowledge among NHTB people compared to EHTB participants. TB becomes uninfectious 2 weeks after a person has been on treatment. Lack of knowledge of this fact brings exaggerated fear of being in close contact and proximity with the TB patient when he or she is not infectious, leading to social and physical isolation. ${ }^{29}$ It is feasible to conclude that most people do not realize the potential risk of contracting TB infection from people manifesting TB signs who are not yet diagnosed, compared with the lower risk among those infected and on treatment.

\section{Knowledge of presenting signs and symptoms of TB}

Findings from this study show that TB-knowledge levels were specific to some symptoms, eg, coughing and difficulty in breathing, which were mentioned by more participants than other signs. The Chichewa word for TB is directly translated as "big cough". It makes sense, therefore, that these are the symptoms that first come to mind. Other signs of TB, such as night sweats, fever, general body weakness, and production of sputum, were mentioned mostly by EHTB participants. It was thus uncommon for NHTB participants to mention multiple signs and symptoms of TB. Other studies have also found that coughing was a symptom most often mentioned to be characteristic of TB. Few patients have been reported to have mentioned such symptoms as general body weakness, weight loss, and fever, as was the case in the current study. ${ }^{46}$

\section{Risk perceptions}

TB was generally perceived as a dangerous disease with severe consequences and that everyone, including participants, is at risk, as it is an airborne disease. TB was also perceived as a difficult disease because of delays in diagnosis. Most models of behavior change state that risk perception is a prerequisite for behavior change. ${ }^{49}$ The fact that most people believe themselves to be at risk of TB infection may present an opportunity for a campaign that can focus on how people can reduce the risk of infection through early diagnosis and treatment. This can significantly reduce the further spread of TB. It is estimated that each untreatable case can lead to 20 more infections in a year. ${ }^{50}$ Knowledge of the importance of early diagnosis and treatment, which has the potential to reduce further transmission of TB, appeared to be high. However, the ability to go for early diagnosis seemed to have been partly affected by people's low knowledge of most of the symptoms of TB, as well as fear of the perceived consequences of being found with TB. These consequences include social isolation and being suspected of having AIDS. For example, in this study, some EHTB participants reported that they did not know that they had TB until they went for diagnosis. This finding is similar to a report from Tanzania. ${ }^{46}$

\section{TB treatment}

Most participants were aware that if TB-like symptoms were experienced, and diagnosis made early, the disease would be cured. Many people mentioned that accessibility to treatment may not be an issue. The belief among most participants that TB is treatable and that drugs are available is an opportunity and entry point for a campaign to promote early diagnosis seeking, which can lead to early treatment and reduced burden of TB.

\section{Fear of being diagnosed with TB}

Participants in this study expressed the fear of being found with TB: especially what their friends would say, being thought to have AIDS due to AIDS and TB sharing similar signs and symptoms, being unable to work properly again, and the policy of screening for HIV in any TB patient and screening for TB in every HIV-infected person. This practice in the health care systems generates negative perceptions and/or misconceptions at times. These findings are similar to findings of studies conducted in Tanzania and Ghana, where TB symptoms, such as physical frailty and extreme weight 
loss, have made some people link HIV to TB. ${ }^{46,51}$ This leads to fear of infection, which may persist even after the person has been successfully treated. Other studies have also found that fear of infection and discrimination tend to persist until treatment completion. ${ }^{51}$ This exaggerated fear may be due to lack of knowledge of the infectiousness of TB prior to and shortly after the onset of treatment. The fear of infection also made people with TB restricted in their use of separate eating utensils. These perceptions make most TB-infected people express the fear of disclosure, and this could affect their intention to present early for diagnosis.

\section{Misguidance regarding treatment compliance}

This study has shown that people diagnosed with TB are advised to refrain from drinking beer, smoking, and having frequent sex. Avoidance of sex was a concern among most male participants, as was the case in Zambia. ${ }^{29}$ A lack of proper explanation and information about these restrictions may also affect people's desire to present for diagnosis. One study conducted in Malawi found that $94 \%$ of TB patients said they could not have sex in the initial phase of TB treatment, while $58 \%$ said they could have sex during the continuation phase. ${ }^{52}$ Reasons given for not having sex included body weakness due to TB, that sex would lead to recurrence of TB, and that sex would inhibit effectiveness of anti-TB drugs. ${ }^{36}$ In terms of health promotion, abstinence from sex, which entails avoidance of close contact during the initial phase of treatment only, may be a good measure, especially among patients who may remain infectious for several weeks. ${ }^{52}$

\section{Family-level factors: role of relatives and friends}

A person with TB should access health services to be diagnosed and treated. However, this is dependent on a number of factors, which include social support. At interpersonal levels, family members, friends, and other close social-circle peers form informal social networks to provide support. ${ }^{53}$ The quality of social support can have an impact on people's adherence to treatment, because of the social consequences of having TB. ${ }^{54}$ This study has shown that females are more likely to provide social support compared with male friends or other community members.

Thus, as a source of social support and potential determinant of health, the family is seen as providing health-related information, reinforcement of psychological resources, self-esteem, and emotional and material support. The family helps in encouraging engagement in health norms and behavior, as well as supporting access to health care. They remind the TB patient to take drugs according to the advice of medical doctors. ${ }^{45,54-57}$ One study conducted in rural Malawi found that people who had been diagnosed with TB disclosed their status, but mostly to people closer to them, such as family members, for fear of being stigmatized, as TB is often linked with AIDS. ${ }^{32}$ This study has shown that mixed family-member responses exist where provision of necessary support to TB patients is concerned. The fear of associating with people with TB was less common among family members compared with friends. A study in Nicaragua also found that family members had the most homogeneous and supportive feelings and behavior, while the community developed more fears, isolation, and mistrust, and friends were described as being in between. ${ }^{58}$

In Ghana, one study found that lack of social support, especially from close family members, was a significant determinant in defaulting from treatment. ${ }^{59}$ Another study in Uganda demonstrated similar trends where people infected with TB are reported to have chosen to limit their diagnosis as a secret to within the family, because family members reacted well and offered care. ${ }^{60}$ Findings also showed that the strength of social support was dependent on the closeness of the relationship. Social support was stronger among family members and friends and very weak among community members. Closefamily members provide support to the person diagnosed with TB. Health-education campaigns should thus promote social support from not only family members but the entire community as well.

\section{Effects on marriage}

There is a case in this study where a man was being pressured by his family to divorce his wife who was diagnosed with TB. Studies in other countries have also shown that people infected with TB experience problems with marriage and that this mostly affects women, and such challenges are, in most cases, long term. ${ }^{6}$ The current study has shown that the spouse returned to her matrimonial home after the partner was cured. This may be as a result of the belief that TB is curable, but also a lack of knowledge that TB infectiousness stops a few weeks after a person has been on treatment.

\section{Sex roles}

Traditionally, women have been ascribed the role of taking care of the health of the family, as well as the community. ${ }^{61,62}$ From a tender age, girls are socialized to be caregivers, eg, by nursing and caring for children and sick people. Girls grow up bearing the burden of ensuring the health of the family. ${ }^{62}$ 
This current study shows that women play the role of caregivers, and this is due to the roles ascribed to men and women from a tender age. Most of the support for persons diagnosed with TB came from women, especially wives. EHTB females reported having received support from their daughters.

\section{Community-level factors}

At the community level, an individual interacts with different environments, including groups of people who have a normative influence on their life.

\section{TB- and HIV-related stigma and discrimination}

There seem to be strong community perceptions that link TB to HIV, making TB a stigmatized disease. While some participants, especially females, expressed sympathy toward people who have been infected with TB, stigma and discrimination were evident. The physical frailty shared between AIDS and TB patients led people to suspect HIV. Furthermore, the use of figurative language to explain TB signs is in itself stigmatizing, as TB-infected people are referred to as "like a person suffering from cholera". This may fuel community perceptions of behavior toward TB patients and may determine how community and society respond to the threat of TB. All this was taking place in an environment where expressions related to caregiving and support were high, such as "these people need our help", or "they must seek medical help quickly". The feeling that if found with TB one will face stigma and discrimination could possibly deter people from seeking diagnosis and to hide symptoms. ${ }^{62}$

The strong perception and belief that when one is found with TB, then it means they have HIV provides a potential reason for hiding signs, thereby delaying diagnosis. TBassociated stigma appeared to have been manifested in participants' reaction to the questions "How do you perceive people infected with TB?" and "How would you react if you were diagnosed with TB?" There was contradiction in views regarding how to interact with a person who has TB and the reported discriminatory practices that the community shows against people with TB. While they reported that TB-infected people must not be discriminated against, most participants reported that TB-infected people are discriminated against. One of the reasons given for this was that most people were afraid of being infected with TB. Proximity to a person with TB determines the level of stigma that an individual suffers. The community most distant from the TB patient develops more mistrust and fear of people with TB, thereby discriminating against and stigmatizing them.
These findings are similar to those of other studies where community members' fear of being infected led to stigma and discrimination. ${ }^{23,29,44,46,60,63}$ Even though community members expressed mixed feelings and attitudes toward TB treatment, most participants expressed a fear of being infected with TB and being thought to have AIDS. The attribution of TB signs and symptoms to HIV is a challenge to overcome, as it incorporates misplaced fears of those with no previous history of TB. The fear attached to TB has been documented in many studies..$^{29,45,46,51,60}$ As presented in Figure 1, on one hand, knowledge about TB is relative, whereas beliefs and attitudes toward TB treatment and need for seeking early diagnosis are high. On the other hand, there is fear of contagion because of the social consequences of being diagnosed with TB, which consequently affects people's intention to seek health care.

\section{Policy: health-system mismanagement}

Findings from this study show that the health-care system plays a significant role in determining community attitudes toward diagnosis seeking. Accounts from participants show that the inability of community-level health facilities to diagnose TB and provide referrals in good time is a potential barrier to diagnosis seeking. This should be looked at in the context of other factors, such as time and cost of travel, as well as the other social consequences of being found with TB. Like other countries in the region, Malawi has high levels of poverty. Poverty not only affects vulnerability to TB but also affects access to services. The diagnosis of TB is complex, requiring repeated trips to health facilities and transport challenges. Sputum has to be transported to a diagnostic facility, with attending difficulty in the communication of results. ${ }^{64}$ In Malawi, TB diagnosis is centralized, but treatment is decentralized to rural communities. Delays in diagnosis, therefore, are real and affect people's confidence to seek early diagnosis.

\section{Challenges affecting health systems}

While delays in diagnosis have been partly influenced by individual-level factors, findings show that poor service delivery within health-care systems has contributed considerably to the delays encountered. ${ }^{53,65}$ Most EHTB participants experienced delays in diagnosis, due to lack of definitive diagnosis. The problems encountered include difficulties in accessing diagnostic services, misdiagnosis, delay in getting results and starting treatment. There is a need to address this situation, as well as to strengthen laboratory services through improvement of diagnostic services at community health-facility levels. Issues of referrals and diagnosis delays due to provider delays must also be looked into, in order to speed up diagnosis of TB. 


\section{Conclusion}

The study illustrated the significance of and obtainment of insights into the perceptions and understandings of TB within a broader context in a rural community. Although it is acknowledged that those who had TB were more knowledgeable, one could establish the knowledge gap in terms of the route of spread and the misconceptions thereof, complicated by the similar symptoms of AIDS, and hence the need for more in-depth health education. Despite the complexity of the disease, there are positive attitudes and beliefs among participants once TB is diagnosed. These include the desire to go for treatment and follow medical advice, as well as the condemning of discriminatory practices. Of importance was also the amount of support provided at the family level, which could be promoted at the community level also. Although participants indicated intentions to seek medical attention in early symptoms stages and expected to get a prompt diagnosis, there was still a knowledge gap in terms of when to suspect symptoms suggestive of TB and the benefits thereof. The strong belief about the treatment and management of TB provides an opportunity to demystify fears that people may have and to promote early diagnosis. On the other hand, the stigma associated with being diagnosed with $\mathrm{TB}$, especially the fear of being infected and the social consequences that follow, constitute a barrier. The suspected shortfall of health-education campaigns and any information-dissemination attempts to emphasize the infectiousness of TB, before and after being put on treatment, are missed opportunities to reduce the stigma and social isolation that result from fear of infection.

\section{Recommendations}

The findings in this study can be used to design a comprehensive health-education campaign, which can encourage early diagnosis and treatment of TB, significantly reduce prevailing stigma and discrimination at household and community levels, encourage participation of men in TB care, and ensure that the health system diagnoses TB quickly. The health-education campaign should clearly state that TB is not transmitted sexually, while explaining the reason for the temporary sexual abstinence that may be required at the early stage of commencing TB treatment while the partner is still sputum-positive.

\section{Acknowledgments}

The authors would like to thank the Ntcheu District TB Office for all the support during this project. We are grateful to the Wellcome Trust for financial support toward the Find TB Research project.

\section{Disclosure}

The authors report no conflicts of interest in this work.

\section{References}

1. Jaramillo E. Encompassing treatment with prevention: the path for a lasting control of tuberculosis. Soc Sci Med. 1999;49:393-404.

2. Raviglione M, Sulis G. Tuberculosis 2015: burden, challenges and strategy for control and elimination. Infect Dis Rep. 2016;8:6570.

3. Sulis G, Roggi A, Matteelli A, Raviglione MC. Tuberculosis: epidemiology and control. Mediterr J Hematol Infect Dis. 2014;6:e2014070.

4. Lönnroth K, Jaramillo E, Williams BG, Dye C, Raviglione M. Drivers of tuberculosis epidemics: the role of risk factors and social determinants. Soc Sci Med. 2009;68:2240-2246.

5. Harper M, Ahmadu FA, Ogden JA, McAdam KP, Lienhardt C. Identifying the determinants of tuberculosis control in resource-poor countries: insights from a qualitative study in the Gambia. Trans $R$ Soc Trop Med Hyg. 2003;97:506-510.

6. Karim F, Johansson E, Diwan VK, Kulane A. Community perceptions of tuberculosis: a qualitative exploration from a gender perspective Public Health. 2011;125:84-89.

7. Long NH, Johansson E, Diwan VK, Winkvist A. Different tuberculosis in men and women: beliefs from focus groups in Vietnam. Soc Sci Med. 1999;49:815-822.

8. Reyes-Guillén I, Sánchez-Pérez HJ, Cruz-Burguete J, Izaurieta-de Juan M. Anti-tuberculosis treatment defaulting: an analysis of perceptions and interactions in Chiapas, Mexico. Salud Publica Mex. 2008;50:251-257.

9. Zhang T, Liu X, Bromley H, Tang S. Perceptions of tuberculosis and health seeking behaviour in rural Inner Mongolia, China. Health Policy. 2007;81:155-165.

10. Liefooghe R, Baliddawa JB, Kipruto EM, Vermeire C, de Munynck AO. From their own perspective: a Kenyan community's perception of tuberculosis. Trop Med Int Health. 1997;2:809-821.

11. Okuonghae D, Omosigho SE. Analysis of a mathematical model for tuberculosis: what could be done to increase case detection. J Theor Biol. 2011;269:31-45.

12. Liefooghe R, Michiels N, Habib S, Moran MB, de Muynck A. Perception and social consequences of tuberculosis: a focus group study of tuberculosis patients in Sialkot, Pakistan. Soc Sci Med. 1995;41:1685-1692.

13. United Nations. The Millennium Development Goals Report: 2015 New York: UN; 2015.

14. World Health Organization. Global Tuberculosis Control. Geneva: WHO; 2010.

15. Hargreaves JR, Boccia D, Evans CA, Adato M, Petticrew M, Porter JD. The social determinants of tuberculosis: from evidence to action. Am J Public Health. 2011;101:654-662.

16. Craig GM, Daftary A, Engel N, O’Driscoll S, Ioannaki A. Tuberculosis stigma as a social determinant of health: a systematic mapping review of research in low incidence countries. Int J Infect Dis. 2017;56:90-100.

17. Dean HD, Fenton KA. Integrating a social determinants of health approach into public health practice: a five-year perspective of actions implemented by CDC's National Center for HIV/AIDS, Viral Hepatitis, STD, and TB Prevention. Public Health Rep. 2013;128:5-11.

18. Centers for Disease Control. Social-ecological model: a framework for violence prevention. 2009. Available from: http://wwwcdcgov/ violenceprevention/overview/social-ecologicalmodel.html. Accessed April 26, 2018.

19. Promtussananon S, Peltzer K. Perceptions of tuberculosis: attributions of cause, suggested means of risk reduction, and preferred treatment in the Limpopo Province, South Africa. J Health Popul Nutr. 2005;23: 74-81.

20. Auer C, Sarol J, Tanner M, Weiss M. Health seeking and perceived causes of tuberculosis among patients in Manila, Philippines. Trop Med Int Health. 2000;5:648-656. 
21. Legesse M, Ameni G, Mamo G, et al. Knowledge and perception of pulmonary tuberculosis in pastoral communities in the middle and lower Awash Valley of Afar region, Ethiopia. BMC Public Health. 2010;10:187-197.

22. Westaway MS. Knowledge and attitudes about tuberculosis of black hospitalised TB patients. Tubercle. 1990;71:55-59.

23. Lönnroth K, Castro KG, Chakaya JM, et al. Tuberculosis control and elimination 2010-50: cure, care, and social development. Lancet. 375:1814-1829.

24. Kanyerere H, Harries AD, Tayler-Smith K, et al. The rise and fall of tuberculosis in Malawi: associations with HIV infection and antiretroviral therapy. Trop Med Int Health. 2016;21:101-107.

25. Dulanya J, Campbell M, Leigh MC. Trying to make a difference: the Malawi experience of a tuberculosis (TB) nurse specialist. Contemp Nurse. 2007;24:93-102.

26. World Health Organization. Malawi: tuberculosis profile. 2016. Available from: https://extranet.who.int/sree/Reports?op=Replet\&name= $\% 2$ FWHO_HQ_Reports\%2FG2\%2FPROD\%2FEXT\%2FTBCountryP rofile\&ISO2=MW\&LAN=EN\&outtype=html. Accessed April 26, 2018.

27. Møller V, Erstad I. Stigma associated with tuberculosis in a time of HIV/AIDS: narratives from the Eastern Cape, South Africa. SAfr Sociol Rev. 2007;38:103-119.

28. Deribew A, Hailemichael Y, Tesfaye M, Desalegn D, Wogi A, Daba S. The synergy between TB and HIV co-infection on perceived stigma in Ethiopia. BMC Res Notes. 2010;3:249-252.

29. Bond V, Nyblade L. The importance of addressing the unfolding TBHIV stigma in high HIV prevalence settings. J Community Appl Soc Psychol. 2006;16:452-461.

30. Needham DM, Bowman D, Foster SD, Godfrey-Faussett P. Patient care seeking barriers and tuberculosis programme reform: a qualitative study. Health Policy. 2004;67:93-106.

31. Ngang PN, Ntaganira J, Kalk A, Wolter S, Ecks S. Perceptions and beliefs about cough and tuberculosis and implications for TB control in rural Rwanda. Int J Tuberc Lung Dis. 2007;11:1108-1113.

32. Zolowere D, Manda K, Panulo B Jr, Muula AS. Experiences of selfdisclosure among tuberculosis patients in rural southern Malawi. Rural Remote Health. 2008;8:1037.

33. Botma Y, Greeff M, Mulaudzi FM, Wright SC. Research in Health Sciences. Portsmouth, UK: P Heinemann; 2010.

34. Groenewald T. A phenomenological research design illustrated. Int $J$ Qual Methods. 2004;3:42-55.

35. Government of Malawi. Ntcheu District Socio-economic Profile. Government of Malawi; 2008.

36. Government of Malawi. National Tuberculosis Control Programme: 5-Year Strategic Plan: 2012-2016. Government of Malawi; 2012. Available from: www.health.gov.mw/index.php/reports?download=27:finaltb-5yr-strategic-plan. Accessed April 5, 2018.

37. Bates I, Fenton C, Gruber J, et al. Vulnerability to malaria, tuberculosis, and HIV/AIDS infection and disease - part 1: determinants operating at individual and household level. Lancet Infect Dis. 2004;4:267-277.

38. Kok M, Muula S. Motivation and job satisfaction of health surveillance assistants in Mwanza, Malawi: an explorative study. Malawi Med J. 2013;25:5-11.

39. DiClemente RJ, Salazar LF, Crosby RA, Rosenthal SL. Prevention and control of sexually transmitted infections among adolescents: the importance of a socio-ecological perspective - a commentary. Public Health. 2005;119:825-836.

40. Kanverere T, Aase A. Delays in TB hospital diagnosis - a major threat for the HIV/AIDS situation in a society: a study of TB as an opportunistic infection in southern Malawi. Nor Geogr Tidsskr. 2005;59:55-64.

41. Galloway RD. Health promotion: causes, beliefs and measurements. $J$ Clin Med Res. 2003;1:249-258.

42. van Zundert RM, Nijhof LM, Engels RC. Testing social cognitive theory as a theoretical framework to predict smoking relapse among daily smoking adolescents. Addict Behav. 2009;34:281-286.
43. Sharma SV, Gernand AD, Day RS. Nutrition knowledge predicts eating behavior of all food groups except fruits and vegetables among adults in the Paso del Norte Region: Qué Sabrosa Vida. J Nutr Educ Behav. 2008; $40: 361-368$.

44. Langenhoven ML, Rossouw JE, Jooste PL, et al. Change in knowledge in a coronary heart disease risk factor intervention study in three communities. Soc Sci Med. 1991;33:71-76.

45. Rundi C. Understanding tuberculosis: perspectives and experiences of the people of Sabah, east Malaysia. J Health Popul Nutr. 2010;28: 114-123.

46. Verhagen LM, Kapinga R, van Rosmalen-Nooijens KA. Factors underlying diagnostic delay in tuberculosis patients in a rural area in Tanzania: a qualitative approach. Infection. 2010;38:433-446.

47. Godfrey-Faussett P, Ayles H. Can we control tuberculosis in high HIV prevalence settings? Tuberculosis. 2003;83:68-76.

48. Mulenga C, Mwakazanga D, Vereecken K, et al. Management of pulmonary tuberculosis patients in an urban setting in Zambia: a patient's perspective. BMC Public Health. 2010;10:756-763.

49. Smith KP, Watkins SC. Perceptions of risk and strategies for prevention: responses to HIV/AIDS in rural Malawi. Soc Sci Med. 2005;60: 649-660.

50. Nyirenda T. Epidemiology of tuberculosis in Malawi. Malawi Med J. 2006:18:147-159.

51. Dador EA, Neal K, Kelly S. An exploration of the causes of tuberculosis stigma in an urban district in Ghana. Int J Tuberc Lung Dis. 2008;12:1048-1054.

52. Salaniponi FM, Christensen JJ, Gausi F, Kwanjana JH, Whitty CJ, Harries AD. "No sex please: we're on TB treatment". Trans R Soc Trop Med Hyg. 2000;94:250-251.

53. Haughton B. Applying the social-ecological model to nutrition issues that promote health and prevent disease. Fam Community Health. 2006;29:3-4.

54. Naidoo P, Mwaba K. Helplessness, depression, and social support among people being treated for tuberculosis in South Africa. Soc Behav Pers. 2010;38:1323-1333.

55. Glanville JL, Bienenstock EJ. A typology for understanding the connections among different forms of social capital. Am Behav Sci. 2009;52:1507-1530.

56. Song L. Social capital and psychological distress. J Health Soc Behav. 2011:52:478-492.

57. Bhandari H, Yasunobu $\mathrm{K}$. What is social capital? A comprehensive review of the concept. Asian J Soc Sci. 2009;37:480-510.

58. Macq J, Solis A, Martinez G, Martiny P, Dujardin B. An exploration of the social stigma of tuberculosis in five "municipios" of Nicaragua to reflect on local interventions. Health Policy. 2005;74:205-217.

59. Dodor EA, Afenyadu GY. Factors associated with tuberculosis treatment default and completion at the Effia-Nkwanta Regional Hospital in Ghana. Trans R Soc Trop Med Hyg. 2005;99:827-832.

60. Macfarlane L, Newell JN. A qualitative study exploring delayed diagnosis and stigmatisation of tuberculosis amongst women in Uganda. Int Health. 2012;4:143-147.

61. Berg JA, Woods NF. Global women's health: a spotlight on caregiving. Nurs Clin North Am. 2009;44:375-384.

62. Kabira WM, Gachukia EW, Matiangi FO. The effect of women's role on health: the paradox. Int J Gynaecol Obstet. 1997;58:23-34.

63. Møller V, Erstad I, Cramm JM, et al. Delays in presenting for tuberculosis treatment associated with fear of learning one is HIV-positive. Afr J AIDS Res. 2011;10:25-36.

64. Simwaka B, Bello G, Banda H, Chimzizi R, Squire B, Theobald S. The Malawi National Tuberculosis Programme: an equity analysis. Int J Equity Health. 2007;6:24.

65. Skordis-Worrall J, Hanson K, Mills A. Confusion, caring and tuberculosis diagnostic delay in Cape Town, South Africa. Int J Tuberc Lung Dis. 2010;14:171-180. 
The Journal of Multidisciplinary Healthcare is an international, peerreviewed open-access journal that aims to represent and publish research in healthcare areas delivered by practitioners of different disciplines. This includes studies and reviews conducted by multidisciplinary teams as well as research which evaluates the results or conduct of such teams or health care processes in general. The journal covers a very wide range of areas and welcomes submissions from practitioners at all levels, from all over the world. The manuscript management system is completely online and includes a very quick and fair peer-review system. Visit http://www.dovepress.com/ testimonials.php to read real quotes from published authors.

Submit your manuscript here: https://www.dovepress.com/journal-of-multidisciplinary-healthcare-journal 